Case Reports in
Gastroenterology
Case Rep Gastroenterol 2021;15:359-364

DOI: 10.1159/000514397

Published online: March 12, 2021

This article is licensed under the Creative Commons Attribution-NonCommercial 4.0 International License (CC BY-NC) (http://www.karger.com/Services/OpenAccessLicense).

Usage and distribution for commercial purposes requires written permission.

\title{
Hematemesis, a Rare Presentation for Downhill Esophageal Varices
}

\author{
Jeremy Van ${ }^{a} \quad$ Shubha Singh ${ }^{b}$ \\ aDepartment of Internal Medicine, Rush University Medical Center, Chicago, IL, USA; \\ bDepartment of Gastroenterology, Rush University Medical Center, Chicago, IL, USA
}

\section{Keywords}

Esophagus · Esophageal varices · Downhill varices · Gastrointestinal bleeding

\begin{abstract}
Downhill esophageal varices (DEV) are a rare form of esophageal varices associated with superior vena cava obstruction. Obstruction leads to retrograde blood flow through collateral venous channels, including the esophageal venous plexus, to redirect blood flow to the right atrium via the inferior vena cava. This leads to the formation of DEV. It is a rare phenomenon to have gastrointestinal bleeding, especially hematemesis, on a patient's first presentation with this disease process. We describe such a case here involving a patient with DEV secondary to metastatic renal cell carcinoma presenting with hematemesis.
\end{abstract}

(C) 2021 The Author(s)

Published by S. Karger AG, Basel

\section{Introduction}

Downhill esophageal varices (DEV) are varices formed from obstructed venous blood flow in the superior vena cava (SVC). When there is obstruction of the SVC, venous flow makes its way back to the right atrium via collateral pathways to the inferior vena cava. One collateral pathway it can take is through the azygos and hemiazygos veins that then flow into the esophageal venous plexus, thus creating DEV $[1,2]$. When the SVC obstruction is above the azygos

\begin{tabular}{ll}
\hline & Jeremy Van \\
Department of Internal Medicine, Rush University Medical Center & \\
& 1717 W. Congress Pkwy, 10th floor \\
Chicago, IL 60612 (USA) \\
jeremy_van@rush.edu
\end{tabular}




\section{Case Reports in Gastroenterology}

Case Rep Gastroenterol 2021;15:359-364

DOI: $10.1159 / 000514397$

(c) 2021 The Author(s). Published by S. Karger AG, Basel www.karger.com/crg

Van and Singh: Hematemesis, a Rare Presentation for Downhill Esophageal Varices

vein, varices form in the upper third of the esophagus, whereas if obstruction is at the level of or below the azygos vein, varices form throughout the entire esophagus [1].

DEV are caused by either extrinsic compression of the SVC or an intrinsic venous disease process in the SVC. Extrinsic compression can occur from a mass effect such as from surrounding malignancy and mediastinal fibrosis [3, 4]. Intrinsic venous disease can occur from SVC thrombosis, complications with hemodialysis catheters, and Behcet's disease, for example [3, 4].

A rare complication of DEV is gastrointestinal (GI) bleeding which represents about 0.4$10 \%$ of all esophageal variceal bleeds $[5,6]$. Less than $0.1 \%$ of patients present with hematemesis $[5,6]$. Those who have a long-term venous catheter complicated by SVC narrowing, due to endothelial injury or thrombosis, make up the population with the highest DEV bleeding risk (around 27\%) [1,7]. Only 14\% of DEV cases secondary to malignancy are complicated by bleeding [1, 7]. The case presented here highlights the rare presentation of hematemesis secondary to DEV in the setting of extrinsic SVC compression from metastatic renal cancer.

\section{Case Report}

A 65-year-old male with a past medical history of renal cell carcinoma with metastasis to the brain and mediastinum, status post right nephrectomy, on nivolumab presented as an outside hospital transfer with a 1-day history of hematemesis. His vital signs included blood pressure $93 / 75 \mathrm{~mm} \mathrm{Hg}$, heart rate 136 , temperature $96.9^{\circ} \mathrm{F}$, respiratory rate 18 , and $\mathrm{SpO}_{2} 100 \%$. He was noted to have a hemoglobin ( $\mathrm{Hgb})$ of $13.1 \mathrm{~g} / \mathrm{dL}$ at the outside hospital, but on arrival he had $800 \mathrm{~mL}$ of hematemesis with a Hgb of $9.1 \mathrm{~g} / \mathrm{dL}$. Other significant labs included total bilirubin $0.5 \mathrm{mg} / \mathrm{dL}$, alkaline phosphatase $81 \mathrm{U} / \mathrm{L}$, AST $14 \mathrm{U} / \mathrm{L}$, ALT $8 \mathrm{U} / \mathrm{L}$, and INR 1.17. He had no prior history of an esophagogastroduodenoscopy (EGD). An EGD (shown in Fig. 1) was completed and demonstrated large downhill varices in the mid-esophagus with white nipple sign and no active bleeding. There was also a normal examined stomach and duodenum without varices. Endoscopic intervention was not completed as there was no active bleeding. Vascular duplex ultrasonography of the abdomen (shown in Fig. 2) demonstrated patency of the portal vein. Computed tomography (CT) of the chest with intravenous (IV) contrast (shown in Fig. 3) showed a $4.6 \times 4.0 \mathrm{~cm}$ necrotic right paratracheal lymph node compressing the bilateral distal brachiocephalic veins (right greater than left) and proximal SVC without evidence of SVC thrombosis. SVC stent placement was not completed given the patient's significant GI bleed and concern for re-bleed if placed on antiplatelet medications. Surgical resection was not undertaken given the precarious location of the enlarged lymph node, the hemodynamic stability of the patient, and lack of further episodes of hematemesis after endoscopy. It was decided in a multidisciplinary conference to deliver 5 doses of $400 \mathrm{cGy}$ radiotherapy to the lymph node to decrease SVC compression. Radiotherapy was completed without complications. The patient was discharged with a stable $\mathrm{Hgb}$ of $8.1 \mathrm{~g} / \mathrm{dL}$ and without further hematemesis or lower GI bleeding. He did not require packed red blood cell transfusions during his admission. Unfortunately, the patient's hospital course was complicated by contrast nephropathy and he was unable to get a follow-up CT of the chest with IV contrast. He has continued his current chemotherapy regimen without further reports of GI bleeding.

\section{Karger'=}




\section{Case Reports in Gastroenterology}

\begin{tabular}{l|l}
\hline Case Rep Gastroenterol 2021;15:359-364 \\
\hline DOI: 10.1159/000514397 & $\begin{array}{l}\text { @ 2021 The Author(s). Published by S. Karger AG, Basel } \\
\text { www.karger.com/crg }\end{array}$ \\
\hline
\end{tabular}

Van and Singh: Hematemesis, a Rare Presentation for Downhill Esophageal Varices

\section{Discussion}

DEV are a rare form of varices first described in 1964 by Felson and Lessure [8]. Another form called uphill esophageal varices (UEV) are found in the setting of portal hypertension [1, $3,7,9]$. UEV tend to have a higher risk for bleeding compared to DEV for a couple of reasons. UEV are found in the superficial sub-epithelium near the gastroesophageal junction, are damaged frequently from refluxed acid, and tend to be found in the setting of coagulopathy secondary to liver dysfunction $[1,3,7,9]$. DEV have a lower risk for bleeding as they are found in the submucosa of the proximal esophagus which provides protection from gastric acid exposure $[1,3,7,9]$. Once DEV are diagnosed on EGD, it is important to evaluate for the underlying etiology.

Currently, there are no standard guidelines for screening or management of DEV. To assist in ruling out portal hypertension as an underlying etiology, imaging of the portal vein should be undertaken, for example with vascular duplex ultrasonography [1]. To better evaluate for extrinsic compression and intrinsic disease of the SVC, the gold standard imaging test is direct venography [3]. CT angiography of the chest can also be used if there is a contrast injection protocol instituted to minimize flow artifacts [3].

When preparing a treatment plan, the underlying etiology of DEV should be targeted. For example, with extrinsic compression of the SVC from cancer, a variety of modalities such as resection, chemotherapy, radiotherapy, and stenting of the SVC can be completed depending on the circumstances of the patient's case, comorbidities, and preoperative mortality [4]. For intrinsic vessel disease, in the setting of thrombosis or stenosis, angioplasty with or without stenting and rarely vascular reconstruction are performed $[3,4,10]$.

Endoscopic interventions on DEV can be completed with either banding or sclerotherapy, but these are temporizing measures used for active bleeding. The risk of bleeding and perforation are high with these procedures because the proximal posterior esophageal wall is weak and there is a lack of serosa in this area [1]. Out of the two modalities, banding is preferred because when sclerosant is injected in the upper and mid-esophagus, there is potential risk of spinal cord infarction with retrograde flow of sclerosant to spinal veins $[1,2,9]$.

DEV are a rare etiology of GI bleeding, especially hematemesis on first presentation of the disease process. When varices are discovered on EGD, with no evidence of underlying portal hypertension, it is important to evaluate for SVC obstruction.

\section{Statement of Ethics}

Written informed consent was obtained from the patient for publication of this case report and any corresponding images.

\section{Conflict of Interest Statement}

The authors have no conflicts of interest to declare.

\section{Karger' $=$}




\section{Case Reports in Gastroenterology}

\section{Funding Sources}

None to report.

\section{Author Contributions}

Jeremy Van's contributions included direct involvement in this patient's care, conception and design of the project, literature review, and writing the manuscript. Shubha Singh's contributions included direct involvement in this patient's care, conception and design of the project, supervision over the project, and review of the manuscript. All authors read and approved the final manuscript.

\section{References}

1 Chakinala RC, Kumar A, Barsa JE, Mehta D, Haq KF, Solanki S, et al. Downhill esophageal varices: a therapeutic dilemma. Ann Transl Med. 2018 Dec;6(23):463.

2 Hussein FA, Mawla N, Befeler AS, Martin KJ, Lentine KL. Formation of downhill esophageal varices as a rare but serious complication of hemodialysis access: a case report and comprehensive literature review. Clin Exp Nephrol. 2008 Oct;12(5):407-15.

3 Gebreselassie A, Awan A, Yaqoob H, Laiyemo A. Superior vena cava obstruction: A rare cause of recurrent esophageal variceal bleeding. Cureus. 2018 Feb;10(2):e2226.

4 Ontanilla Clavijo G, Trigo Salado C, Rojas Mercedes N, Caballero Gómez JA, Rincón Gatica A, Alcívar-Vasquez JM, et al. Downhill varices: an uncommon cause of upper gastrointestinal bleeding. Rev Esp Enferm Dig. 2016 Jul;108(7):440-2.

5 Rhoades DP, Forde KA, Tabibian JH. Proximal esophageal varices: A rare yet treatable cause of hemorrhage. Clin Gastroenterol Hepatol. 2016 Sep;14(9):e105-6.

6 Nguyen LP, Sriratanaviriyakul N, Sandrock C. A rare but reversible cause of hematemesis: "Downhill" Esophageal Varices. Case Rep Crit Care. 2016;2016:2370109.

7 Loudin M, Anderson S, Schlansky B. Bleeding 'downhill' esophageal varices associated with benign superior vena cava obstruction: case report and literature review. BMC Gastroenterol. 2016 0ct;16(1):134.

8 Felson B, Lessure AP. “Downhill” varices of the esophagus. Dis Chest. 1964 Dec;46(6):740-6.

9 Heller SL, Meyer JR, Russell EJ. Spinal cord venous infarction following endoscopic sclerotherapy for esophageal varices. Neurology. 1996 Oct;47(4):1081-5.

10 Raghavapuram S, George N, Girotra M, Siddique S, Tharian B. Downhill esophageal varices: unusual cause of hematemesis. VideoGIE. 2017 Apr;2(9):231-2. 
Case Reports in Gastroenterology
Case Rep Gastroenterol 2021;15:359-364

DOI: 10.1159/000514397

(c) 2021 The Author(s). Published by S. Karger AG, Basel www.karger.com/crg

Van and Singh: Hematemesis, a Rare Presentation for Downhill Esophageal Varices
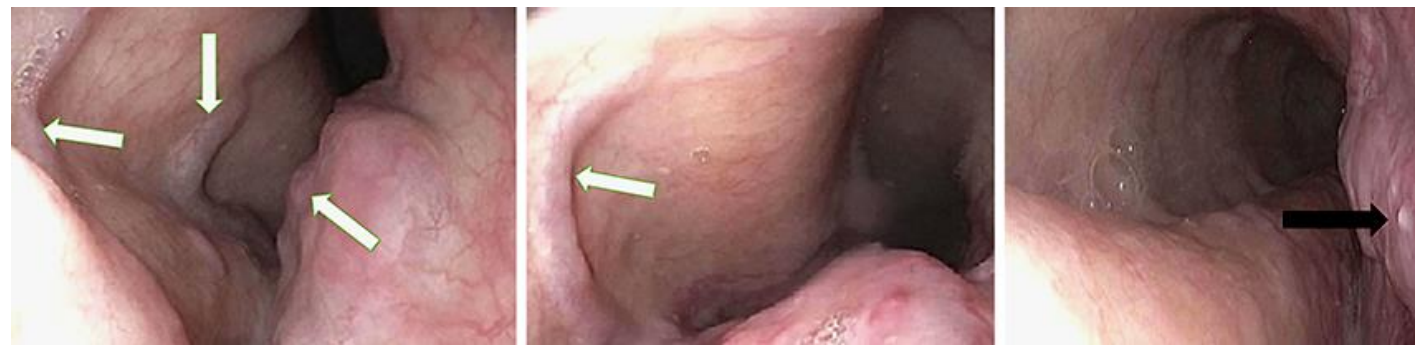

Fig. 1. Esophagogastroduodenoscopy demonstrates large downhill varices (white arrows) in the midesophagus with white nipple sign (black arrow) and no evidence of active bleeding.

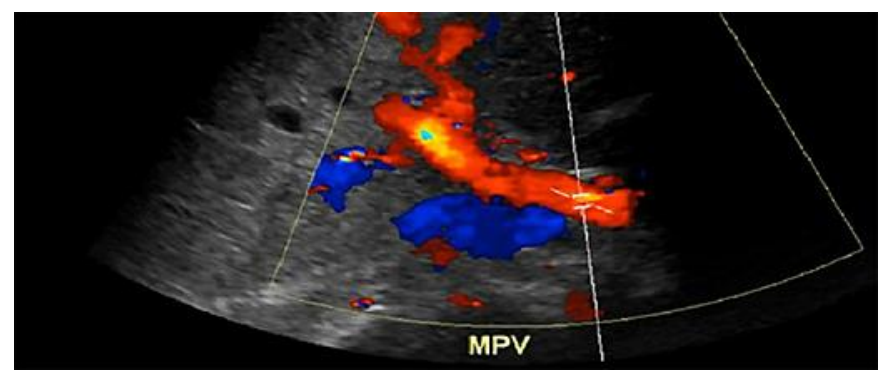

Fig. 2. Vascular duplex of the abdomen demonstrates patency of the main portal vein with hepatopetal color Doppler flow and spectral duplex waveform with a normal velocity of 48-60 cm/s. Red: flow towards transducer; blue: flow away from the transducer. Lighter color indicating higher velocity flow. 
Case Reports in Gastroenterology
Case Rep Gastroenterol 2021;15:359-364

DOI: $10.1159 / 000514397$

(c) 2021 The Author(s). Published by S. Karger AG, Basel www.karger.com/crg

Van and Singh: Hematemesis, a Rare Presentation for Downhill Esophageal Varices

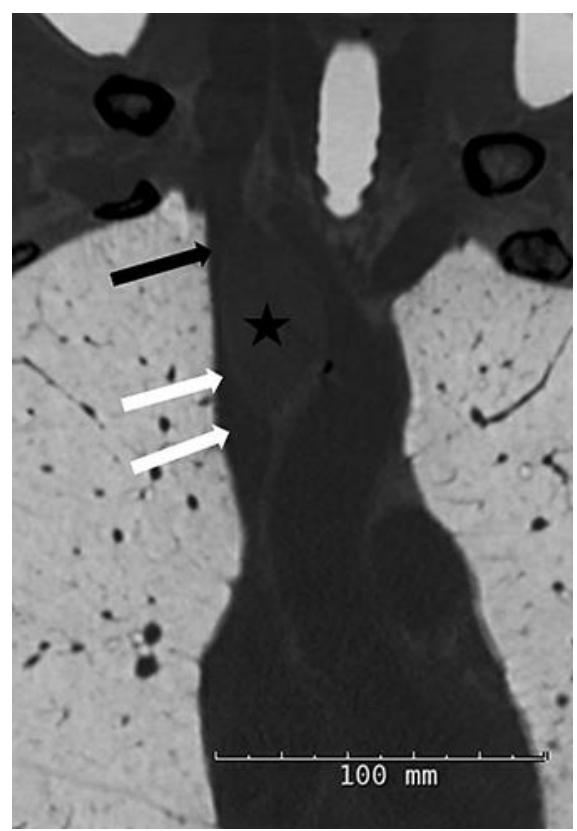

Fig. 3. Computed tomography of the chest with intravenous contrast (coronal view) demonstrates a $4.6 \times$ $4.0 \mathrm{~cm}$ right paratracheal lymph node (black star) compressing the distal brachiocephalic veins (black arrow pointing to the right brachiocephalic vein) and proximal superior vena cava (outlined by white arrows) with no evidence of thrombosis. 